\title{
Concept of an Electromagnetic Solar Based Power Drive for Automobile
}

\author{
Shirsendu Das ${ }^{1}$ and Amit Kumar ${ }^{2}$ \\ ${ }^{1}$ National Institute of Technology Agartala, Jirania \\ ${ }^{2}$ Baba Saheb Dr. Bheem Rao Ambedkar College of Ag. Engineering \& Technology, \\ U.P
}

\begin{abstract}
Concept of using solar energy to run vehicles has been introduced many times in many countries. But the stored amount of energy can run vehicle for limited time or only during day times. In the traditional technique of 'solar powered vehicle' a motor is drive by battery which is recharged by solar energy. Here, we have introduced a solar charged electromagnetic mechanism, where the both attractive \& repulsive effect of two similar dissimilar poles will be responsible for piston's reciprocation \& will produce sufficient shaft power.
\end{abstract}

Keywords: Electromagnetism, magnetic field, distributer mechanism

\section{Introduction}

This mechanism consists of piston, connecting rod, crank-shaft etc like normal IC Engine. But there is no necessity of spark plug, valve mechanism, fuels \& fuel injection systems. The piston of this mechanism is made with a bar magnet or permanent magnetic materials, which is trusted by both the attractive $\&$ repulsive action/force of solenoids. The solenoids are placed at the top dead centre (TDC) \& bottom dead centre (BDC) of each cylinder. The required electricity to magnetize the solenoids is supplied by battery, which is charged by solar power.

\section{About Traditional IC Engine \& Environmental Impacts:}

Suction, compression, power \& exhaust are the consecutive strokes of normal IC engines to produce two or one revolution of crank-shaft. These engines are run by petrol, diesel or other hydrocarbon fuels \& escape large or less amount of exhaust gases (CO, $\mathrm{CO}_{2}, \mathrm{NO}_{\mathrm{X}}$ etc) which are responsible for environmental pollution \& global warming. But in case of this mechanism no fuel is required so there is no chance of pollution.

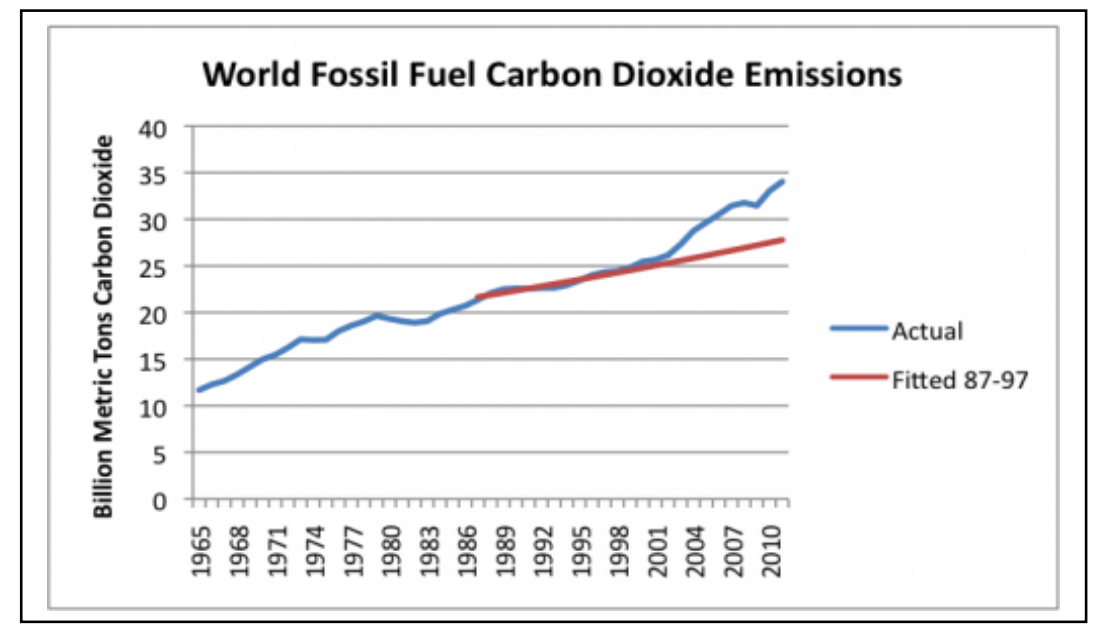




\section{Working of this Mechanism:}

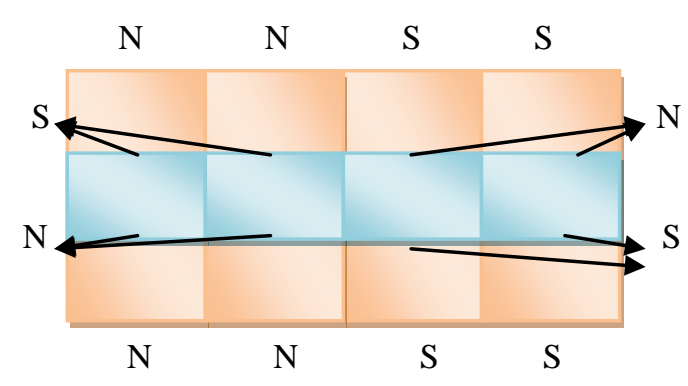

Figure 1

Figure 1 represents the cylinders \& pistons of the given mechanism. Cylinders should make with non-magnetic materials like aluminum alloy \& forged steel etc. Pistons are permanent magnets and there poles are represented in fig- 1 . N-Poles will generate at the TDC of cylinder-1 \& 2 and S-Poles at the BDC of same cylinders with the help of solenoids. Similarly S-Poles will generate at the TDC of cylinder-3 \& 4 and N-poles at the BDCs of same cylinders.

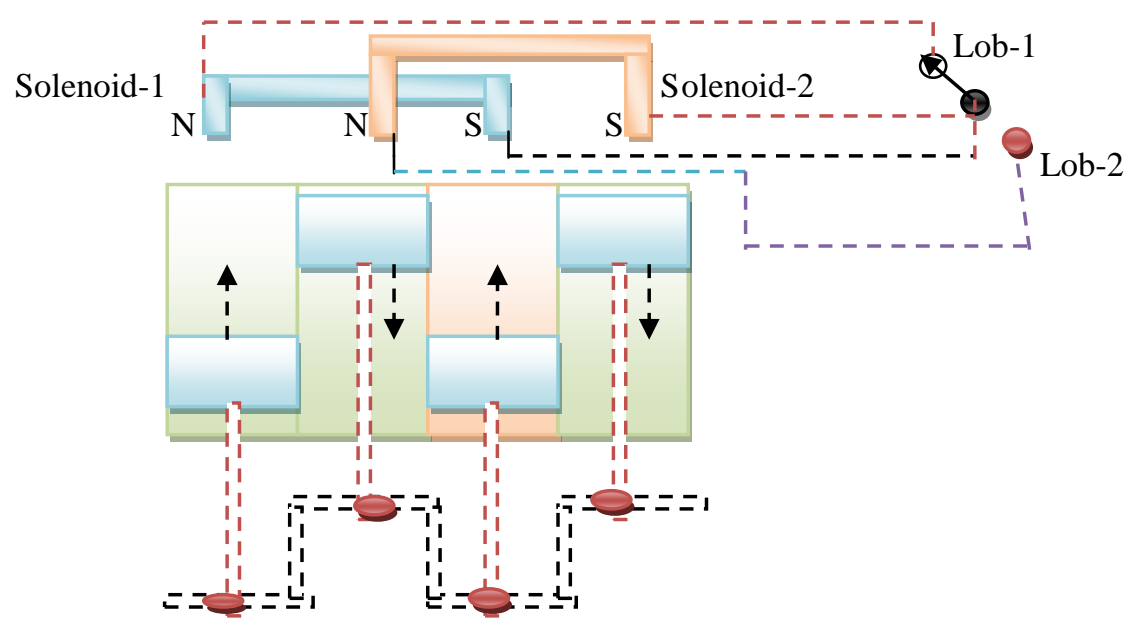

Figure 2

Figure 2 represents the connection of solenoids with distributers. Solenoids are also available at the BDC (Figure 3) which are also run by another distributor. Distributors of the mechanism are run by crank shaft $\&$ will have same r.p.m of the crank shaft. Initially pistons $1 \& 3$ are at BDC and $2 \& 4$ are at TDC. That time both the distributor arms touch lob-1 \& 3, so the solenoid $1 \& 3$ will be magnetized. The S-pole of piston- 1 will attract by $\mathrm{N}$-pole of solenoid-1 \& on the other hands N-pole will repulse by the N-pole of solenoid3 . Due these attractive and repulsive effects piston- $1 \& 3$ will move very fast to the TDC and piston- $2 \& 4$ will move to BDC. At the same time the crank-shaft will rotate half revolution. So the distributors will rotate another half revolution \& arms will touch iob-2 $\& 4$ for which solenoid- $2 \& 4$ will magnetized. Now again the piston -2 will attract by the N-pole of solenoid-2 \& repulse by the N-pole of solenoid-4. Same thing will happen for piston- 4 also. So the piston- $\& 4$ will move to TDC due to attractive \& repulsive thrust $\&$ the shaft will revolve another half revolution. At the same time the piston- $1 \& 3$ again come to BDC and the same process will continue. 
Loob-4

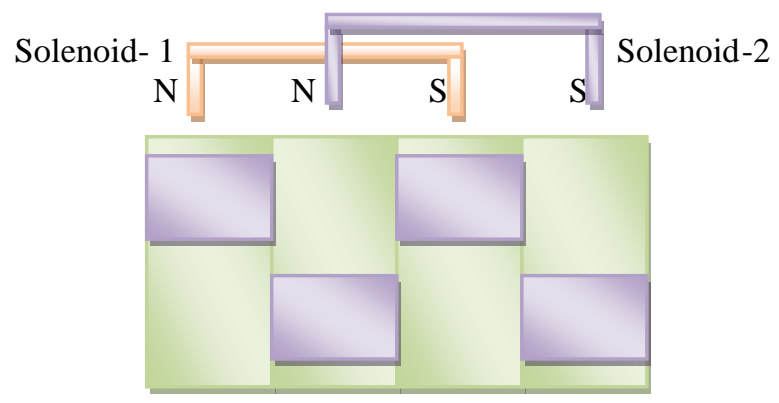

Lob-3

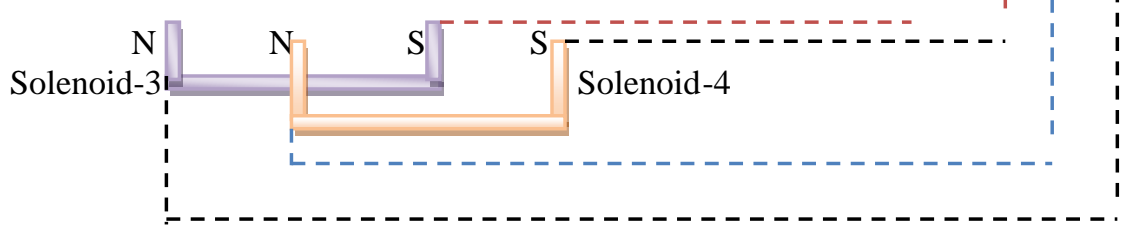

Figure 3

Results are enlisted with various position bellows:

\begin{tabular}{lccc}
\hline Piston & Position of Piston & Arm in Distributor- & Arm in Distributor-2 \\
& & 1 & \\
Piston-1 & TDC & Lob-2 & Lob-4 \\
Piston-1 & BDC & Lob-1 & Lob-3 \\
Pston-2 & TDC & Lob-1 & Lob-3 \\
Piston-2 & BDC & Lob-2 & Lob-4 \\
Piston-3 & TDC & Lob-2 & Lob-4 \\
Piston-3 & BDC & Lob-1 & Lob-3 \\
Piston-4 & TDC & Lob-1 & Lob-3 \\
Piston-4 & BDC & Lob-2 & Lob-4 \\
\hline
\end{tabular}

\section{Flow Diagram of Solar Power Conversion:}

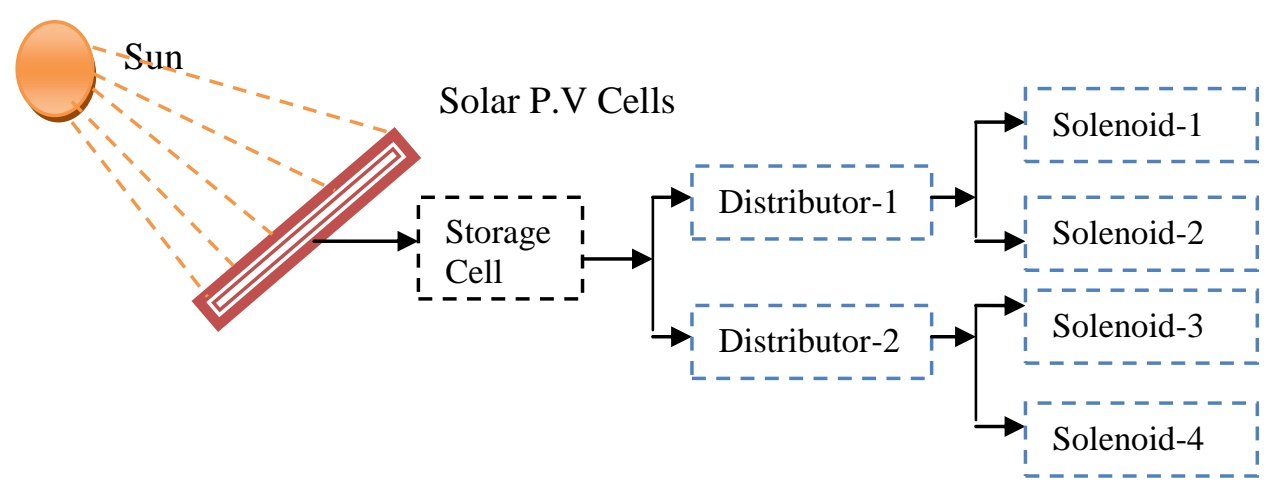

\section{Calculation for Power Output:}

Power output of this mechanism can be calculate with the help of this formula,

Power $(\mathrm{P})=\left(\mathrm{F}_{\mathrm{P}} \mathrm{LN}\right) / 60$

Where, $\mathrm{F}_{\mathrm{P}}=$ force or thrust or attractive force or repulsive force on the piston. $\mathrm{L}=$ stroke length, $\mathrm{N}=$ r.p.m.

Force exerts on piston due to attractive \& repulsive effect $\left(\mathrm{F}_{\mathrm{P}}\right)=\left(\mathrm{f}^{2} \mathrm{~A}^{2} \times 10^{-7}\right) / 4 \pi \mathrm{N}$.

Where, $\mathrm{f}=$ Magnetic flux density $\left(\mathrm{Wb} / \mathrm{m}^{2}\right), \mathrm{A}=$ Cross-sectional area of piston. 
Required magnetic field \& current correspondence to different I.P for this mechanism has been enlisted here for single cylinder mechanism.

\begin{tabular}{ccccc}
\hline H.P & Magnetic Flux & Flux Density & Current & Force on piston \\
2.5 & $0.0021 \mathrm{~Wb}$ & $0.008 \mathrm{~Wb} / \mathrm{m}^{2}$ & $1.6 \mathrm{amp}$ & $16.67 \mathrm{~N}$ \\
2 & $0.001 \mathrm{~Wb}$ & $0.007 \mathrm{~Wb} / \mathrm{m}^{2}$ & $0.79 \mathrm{amp}$ & $13.34 \mathrm{~N}$ \\
3 & $0.0025 \mathrm{~Wb}$ & $0.009 \mathrm{~Wb} / \mathrm{m}^{2}$ & $1.99 \mathrm{amp}$ & $20 \mathrm{~N}$ \\
1.5 & $0.0016 \mathrm{~Wb}$ & $0.006 \mathrm{~Wb} / \mathrm{m}^{2}$ & $1.27 \mathrm{amp}$ & $10 \mathrm{~N}$ \\
1 & $0.0014 \mathrm{~Wb}$ & $0.005 \mathrm{~Wb} / \mathrm{m}^{2}$ & $1.12 \mathrm{amp}$ & $6.67 \mathrm{~N}$ \\
\hline
\end{tabular}
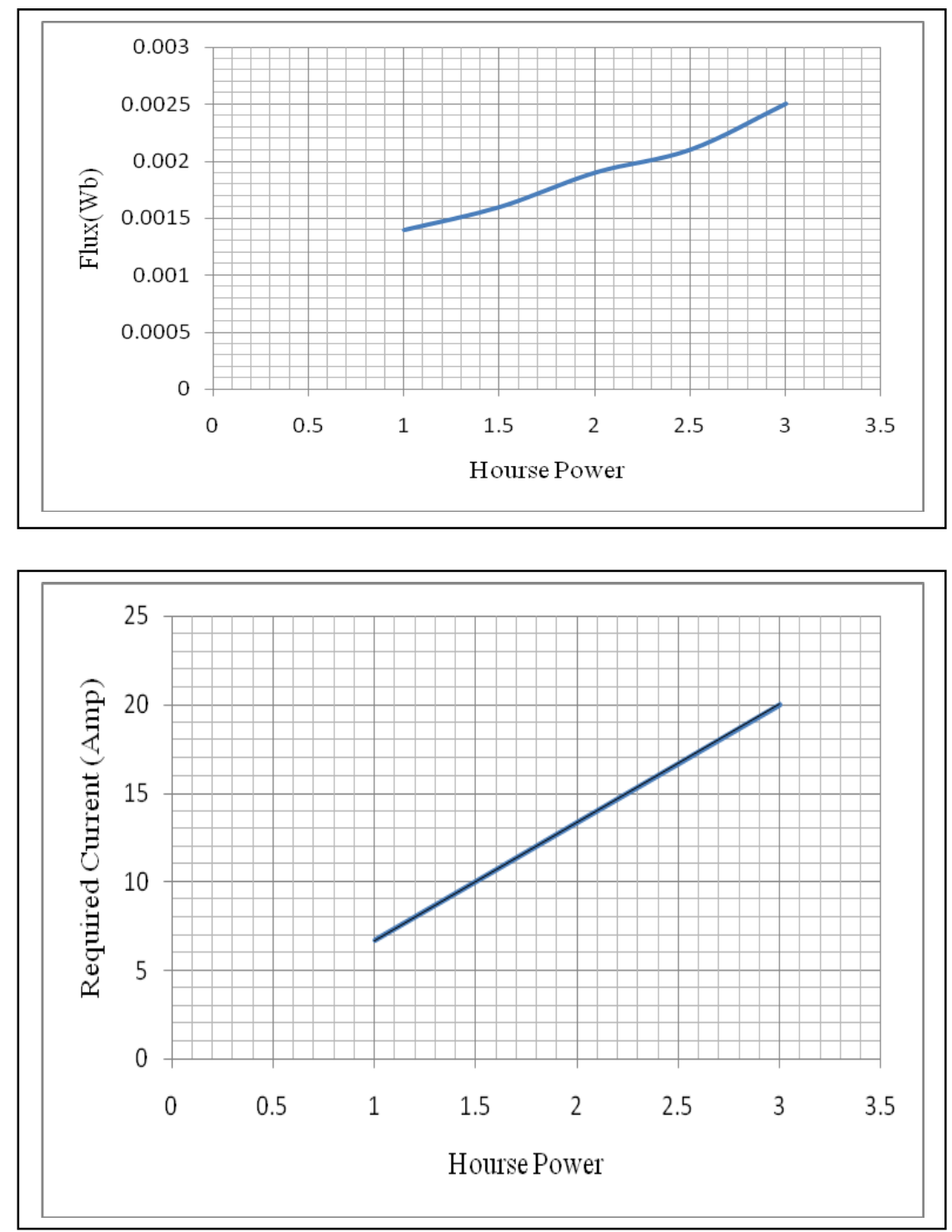

\section{Comparison with Normal IC Engine for Same Piston Thrust:}

Here we have compared the power output of normal I.C Engine with the work output of this mechanism for two revolution of crank-shaft and same piston thrust. Line No-2 (of bellow mentioned figure) represent the mean effective power require to run the engine. Suction, compression \& exhaust strokes consume power from power stroke so their power is negative. The power or expansion stroke produces the sufficient power to run the cycle or engine. 


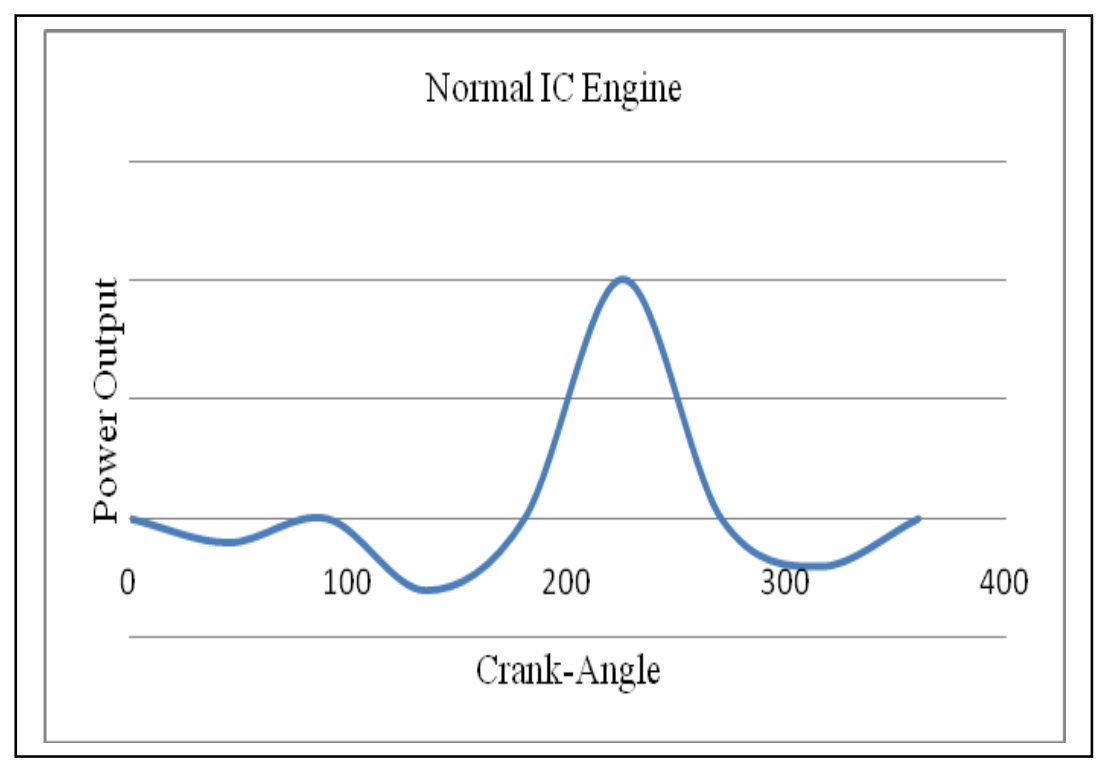

But in this proposed mechanism only has forward (power) \& return strokes. For two complete revolution of crank-shaft the mechanism performs two forward \& two return strokes. Now if the magnetic system produces same thrust on the piston of the mechanism then the power is shown in bellow.

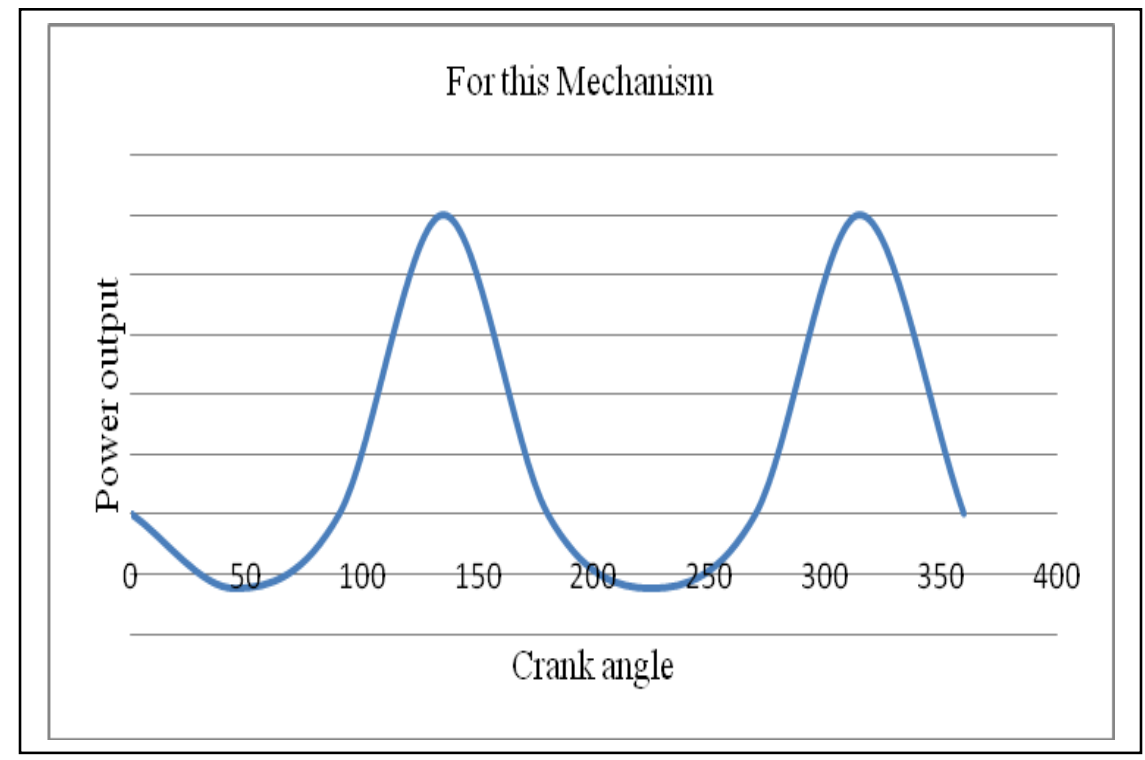

Here, it is proved that if the magnetic thrust on the piston of this mechanism is equals to expansion thrust of IC Engine then this mechanism will give more power output. Not only that if magnetic system's thrust is half of engine thrust then also power output is more \& if one third of engine thrust can provide on the piston of the mechanism it can generate equal power of an engine after two revolution.

\section{Conclusion}

Very minimum amount of electric power is required to magnetize these solenoids time to time \& solar storage cell can supply the sufficient amount of power continuously. So the mechanism can use for long run. On the other hand this mechanism is pollution free \& has no bad environmental impact. Here, it is proved that it can produce sufficient amount of power like IC engines. So, it is very much acceptable in environmental \& pollution aspect. 
International Journal of Advanced Science and Technology

Vol.76 (2015)

\section{References}

[1] S. Das, "An electromagnetic mechanism which works like an engine", International Journal of Engineering trends \& Technology, vol. 4, no. 6, (2013), pp. 2376-2379.

[2] S. Das, "A hydraulic mechanism which works like an engine", International Journal of Scientific \& Engineering Research, vol. 5, no. 1, (2014), pp. 284-288.

[3] Magnetic force calculation from Australian Magnetic Solution (www.magneticsolution.com.au ). 